\title{
La antropología teológica de Populorum Progressio
}

\section{Rafael Amo Usanos'}

Resumen: Pablo VI en Populorum Progressio dibuja una imagen del hombre en diálogo con las corrientes de pensamiento que hicieron del debate antropológico el centro de la discusión. Conocer esa descripción y su contenido teológico, identificar las influencias que ha recibido y apuntar su proyección en los problemas actuales es el objeto de este trabajo.

Palabras Clave: Antropología, desarrollo humano integral, Populorum Progressio.

Fecha de recepción: $28-30$ de junio de $2017^{2}$.

Fecha de admisión definitiva: 21 de junio de 2018.

The theological anthropology of Populorum Progressio

Abstract: Paul VI in Populorum Progressio draws a picture of man in dialogue with the currents of thought which made of the anthropological debate the center of the discussion. To know that description and its theological content, to identify the influences it has received, and to point out its projection
L'anthropologie théologique de Populorum Progressio

Résumé: Paul VI établit dans Populorum Progressio une image de l'Homme en dialogue avec les courants de pensée qui firent du débat anthropologique le centre de la discussion. Connaître cette description et son contenu théologique, identifier les influences reçues et montrer sa projection

\footnotetext{
${ }^{1}$ Universidad Pontificia Comillas.

${ }^{2}$ Fecha de celebración del Simposio.
} 
into the present day problems, is the object of this work.

Key words: Anthropology, integral human development, Populorum Progressio. dans les problèmes actuels est l'objectif de ce travail.

Mots clé: Anthropologie, développement humain intégral, Populorum Progressio.

La década de los años sesenta del siglo XX -en la que se escribe Populorum Progressio ${ }^{3}$ - fue muy bulliciosa en todos los sentidos: movimientos sociales, tensiones políticas, movimientos económicos, avances científicos y médicos, etc.. hasta en la Iglesia Católica que celebró el Concilio Vaticano II. Es muy difícil describir resumidamente una década tan intensa como los años sesenta en cuyo tramo final se publica PP4. Pero este contexto es crucial para entender su antropología. Así lo deja ver Paul Poupard en el mismo año 1967, en un edición francesa de la encíclica Populorum Progressio, donde escribía: "Está muy claro: PP es la contestación, en nombre del Evangelio, a un mundo inhumano"

PP, que pretende ser "una nueva voz para nuestra época" (PP47), se dirige a la Iglesia universal y a todos los hombres de buena voluntad para abordar como tema central el desarrollo humano y sus desequilibrios que están deshumanizando aún más la humanidad. Las consecuencias sobre el ser humano de los cambios de la década de los sesenta ponen en el centro de debate en general y del debate sobre el desarrollo, en particular, a la antropologíá.

Por una parte, el problema del desarrollo, pero también otras corrientes de pensamiento, hicieron del debate antropológico el centro de la discusión. Esto es: no solo el desarrollo tal y como se daba en la década de los sesenta estaba deshuma-

${ }^{3}$ De ahora en adelante se citará como PP. Se utilizará como fuente la versión del texto de la página web del Vaticano: [acceso 27.4.17] http://w2.vatican.va/content/paul-vi/es/encyclicals/documents/ hf_p-vi_enc_26031967_populorum.html

${ }^{4}$ I. Camacho describe brevemente el ambiente de la década en I. CAMACHO (2008) "Modelos y logros del desarrollo internacional", en F. Fuentes Alcántara (ed.), El derecho a un desarrollo integral. Simposio Internacional a los 40 años de Populorum Progressio, Madrid, Edice, 58-59.

5 PABLO VI (1967) Le developpement des Peuples. Texte et commentaire. Introduction por Mgr Poupard, París, Mame, 19.

- Son muchos autores los que afirman que la gran novedad de esta encíclica no es el tema tratado, ni el tono en que lo trata, sino su antropología. Cf. I. CAMACHO (1991) Doctrina Social de la Iglesia. Una aproximación histórica, Madrid, Paulinas, 379, donde cita abundante bibliografía al respecto. 
nizando al hombre, sino que además grandes corrientes de pensamiento del siglo $X X$, están -a juicio de la antropología teológica- haciendo un mundo inhumano.

Pablo VI en PP dibuja una imagen del hombre en diálogo con esas corrientes. Conocer esa descripción y su contenido teológico, identificar las influencias que ha recibido y apuntar su proyección en los problemas actuales es el objeto de este trabajo.

\section{El hombre de PP}

Benedicto XVI, que en Caritas in Veritate se convierte en uno de los mejores intérpretes de PP, afirma que el mensaje central de PP es que el desarrollo debe ser integral, esto es, "de todo el hombre y de todos los hombres"7 y sugiere que profundizando en esta expresión se puede esbozar la antropología teológica de PP. Por fidelidad al texto de PP mantendré el término hombre para referirme a ambos sexos.

\section{I.a. El hombre total, integral, global}

El hombre de PP es un ser de múltiples "cualidades" (PP1). Ya de ellas hablaba Gaudium et Spes 64 cuando al hablar del hombre integral afirmaba que posee necesidades materiales y exigencias intelectuales, morales, espirituales y religiosas ${ }^{8}$.

7 Benedicto XVI, Caritas in Veritate 18:

La verdad del desarrollo consiste en su totalidad: si no es de todo el hombre y de todos los hombres, no es verdadero desarrollo. Éste es el mensaje central de la Populorum progressio, válido hoy y siempre.

A partir de este momento se utilizará la abreviatura CiV y el texto de la página web del Vaticano: [acceso 27.4.17] http://w2.vatican.va/content/benedict-xvi/es/encyclicals/documents/hf_benxvi_enc_20090629_caritas-in-veritate.html

8 Vaticano II, Gaudium et Spes 64:

La finalidad fundamental de esta producción no es el mero incremento de los productos, ni el beneficio, ni el poder, sino el servicio del hombre, del hombre integral, teniendo en cuanta sus necesidades materiales y sus exigencias intelectuales, morales, espirituales y religiosas; de todo hombre, decimos, de todo grupo de hombres, sin distinción de raza o continente.

De ahora en adelante se utilizará la abreviatura GS y se cita el texto de la web del Vaticano: [acceso 27.4.17] http://www.vatican.va/archive/hist_councils/ii_vatican_council/documents/ vat-ii_const_19651207_gaudium-et-spes_sp.html 
Es un ser que "hace, conoce, tiene" (PP6). Esto es, es un ser que se hace en el trabajo (PP21) por medio del cual "coopera con el creador" (PP 27. 28). Es más, es un creador (PP 27).

El hombre es un ser cuya naturaleza le permite poseer. La propiedad es esencial a su naturaleza aunque esta deba ejercerse de una determinada manera (PP 6.23). En este sentido no cabe ningún dual ismo: economía y humanidad no se oponen (PP 14).

El ser humano conoce (PP 6): la cultura y el conocimiento lo definen (PP 21. 27. 40). El ser humano es un ser inteligente (PP 27).

Pero además el ser humano es, al mismo tiempo, natural y sobrenatural (PP 28). Tiene un carácter espiritual (PP 27) capaz de reconocer los valores supremos (PP21) que provienen y tienden a Dios; y de acoger a Dios por la fe, el cual es Padre de todos los hombres (PP 21).

\section{I.b. El hombre del humanismo transcendental}

El hombre de PP está llamado a ser (PP 6) y a ser más hombre (PP 19), obligado a orientarse a Dios y a crecer con ello (PP 16. 15) porque es un ser vocacionado (PP 15). Tiene dentro de sí un conjunto de cualidades a modo de semilla que deben florecer (PP 15). Es decir es un ser dinámico, no anclado en su esencia, un ser que para ser él mismo, debe desarrollar (PP 6) su carácter multidimensional (PP 21).

\section{I.c. El hombre como ser social}

El hombre de PP es miembro de la sociedad, pertenece a la humanidad entera (PP 17). Y solo puede ser más, en todas sus dimensiones, dentro de la sociedad. Ayudado de la familia -célula de la sociedad-alcanza la plenitud de sí mismo (PP 36). Por medio del trabajo, además, descubre que esa sociedad a la que pertenece de modo natural, es una fraternidad (PP 27).

\section{La trama del mundo inhumano}

Como decía Popuard, la antropología de PP es la respuesta de la Iglesia a un mundo inhumano. La explicación de los tres rasgos del hombre que contiene la afirmación "todo el hombre y todos los hombres" pretenden ayudar a hacer más humano un 
mundo que - a juicio de Pablo VI- el materialismo, un determinado existencialismo y el individualismo conducen a condiciones de vida menos humanas.

\section{2.a. El materialismo}

El propio Pablo VI indica cual es la primera causa que hace de su tiempo un lugar inhumano: se trata del materialismo'. Este centra al hombre exclusivamente en las realidades terrenas y le impide el camino de la transcendencia. Es una ideología que considera solo algunos aspectos del ser humano, dejándolo reducido al no considerar los más profundos: entre ellos el religioso ${ }^{10}$.

Ahora bien, el materialismo del que habla Pablo VI tiene dos cabezas. Por un lado el ateísmo (PP 42), y por otro el liberalismo sin freno (PP 26). Ambos crean un mundo inhumano, niegan la dimensión transcendente del ser humano.

Primero Henry de Lubac y después el Concilio Vaticano II en la Constitución Gaudium et Spes (GS 19-20) habían puesto de manifiesto que el ateísmo era un drama para el hombre. No obstante el mismo Pablo VI cita la famosa obra de Henry de Lubac, El drama del humanismo ateo y escribe:

El hombre puede organizar la tierra sin Dios, pero, 'al fin y al cabo, sin Dios no puede menos de organizarla contra el hombre' (PP 42).

Por otra parte, el liberalismo sin freno,

que considera el lucro como motor esencial del progreso económico, la concurrencia, como ley suprema de la economía; la propiedad privada de los medios de producción como un derecho absoluto, sin límites ni obligaciones correspondientes (PP 26),

no levanta la mirada del hombre a Dios, al que excluye de su idea de desarrollo, ni tampoco mira al hombre sino al dinero. Esto lo convierte en la segunda cabeza de la hidra materialista que hace al mundo inhumano.

9 PP 41.

10 D. AlbeRTI (1972) L'umanesimo plenario della Populorum Progressio, Roma, Pontificia Universitas Lateranensis, 16:

La Chiesa difende dunque la verità dell'uomo, dell'uomo completo, non come fanno le ideologie 'che dell'vomo considerano soltanto alcuni aspetti e, fra questi, i meno profondi (MM 198). Ha un'idea ben precisa dell'vomo, e con essa intende contribuire alla soluzione dei problema social e parla un linguaggio universale, valido per ogni vomo, per tutti gli vomini. 


\section{2.b. El humanismo}

El problema antropológico en el siglo XX, y especialmente a raíz de la segunda guerra mundial, se estaba concentrando en su carácter existencial. El tema filosófico por excelencia no era ¿qué es el ser humano? Su esencia. Sino ¿̇cómo se es ser humano? Su existencia.

Era lógico. La metafísica había muerto hacia algunos siglos, pero a inicios del siglo XX Wittgenstein le había dado la puntilla. No se puede abordar el problema de la esencia porque no hay ciencia capaz de ello. Solo nos queda preguntarnos por la existencia. Este problema llega a la antropología cuando se aborda el carácter existencial del ser humano. Esta es la llamada "polémica sobre el humanismo"11.

En los años en los que se escribe la encíclica había adquirido una importancia central. Existía la versión existencialista representada por J. P. Sartre, o la del humanismo socialista en la que se empeñaron nombres tan ilustres como E. Fromm ${ }^{12}$ - Louis Althusser ${ }^{13}$. Pero el humanismo tiene más aristas, entre ellas la cristiana representada, entre otros De Lubac ${ }^{14}$, Alfaro ${ }^{15}$ y, por supuesto, Maritain ${ }^{16}$.

11 L. Althusser, J. Semprún, M. Simon y M. VerRet (1968) Polémica sobre marxismo y humanismo, México, Siglo XXI, 1. Así comienza la Carta sobre el humanismo de Heidegger:

No pensamos aún la esencia del obrar en forma suficientemente decidida. Se conoce el obrar como el impulsar un efecto. Su efectividad es apreciada según su provecho. Pero la esencia del obrar es el llevar a cabo. Llevar a cabo quiere decir: desplegar algo en la plenitud de su esencia, conducir ésta hacia la plenitud, producere. Desplegable es por eso propiamente lo que es. Lo que, sin embargo, ante todo es, el ser.

M. Heidegger (1959) Carta sobre el humanismo, Madrid, Taurus, 7. La bibliografía sobre el humanismo es amplísima, pero algunos breves resúmenes que ayuden a la comprensión: A. PINTOR RAMOS (1997) "Humanismo", en M. Moreno VILLA, Diccionario de pensamiento contemporáneo, Madrid, Paulinas, 627-633.

12 Un destacado autor del humanismo socialista cuyas obras más destacadas son: E. Fromm (2008) El miedo a la libertad, Barcelona, Paidós; E. Fromm (2007) Del tener al ser, Barcelona, Paidós.

${ }^{13}$ L. AlthusSeR (1968) Polémica sobre marxismo y humanismo, México, Siglo XXI.

${ }^{14}$ H. DE LUBAC (1967) El drama del humanismo ateo, Madrid, Epesa.

${ }^{15}$ J. Alfaro (1974) Hacia una teología del progreso humano, Barcelona, Herder.

${ }^{16}$ Su obra más destacada al respecto es J. MARITAIN (1966) Humanismo integral, Buenos Aires, Carlos Lohlé. Siguiendo a Cipriano Calderón se puede afirmar que Maritain fue el autor más influyente sobre 
El humanismo se ocupa fundamentalmente de la existencia humana, y de cómo se despliega. Es decir, la reflexión sobre cómo se es hombre, en qué grado se desarrolla el ser hombre, qué condiciones lo hacen posible, etc. El panorama del humanismo es muy complejo ya que tiene raíces metafísicas, pero facetas ideológicas que lo ponen al servicio de fines y objetivos sociopolíticos ${ }^{17}$. En él se dan cita quienes piensan que el ser humano no tiene esencia sino que es pura existencia condenada a ser libre, o quienes creen que el ser humano tiene una esencia que desplegar, ya sea sin la ayuda de la Transcendencia, o con ella.

\section{2.c. El personalismo}

El humanismo no agotó el debate antropológico del siglo XX, también hubo cabida para el personalismo ${ }^{18}$. La primera denominación de personalismo a un sistema se remonta a la obra de Charles Renouvier en 1903. El clima del siglo XX obligó a algunos autores a reivindicar la dignidad de la persona en el campo ontológico, gnoseológico, moral o social en contra de diversas negaciones como la materialista. Así surge una doctrina filosófica, con multitud de ramas, que centra en el concepto de persona el significado de la realidad.

En el ámbito de esta reflexión se pretende afirmar que la persona es el centro de todo $y$, en concreto, de la sociedad. Por tanto, la persona no se diluye en la sociedad, como afirmaba el marxismo; pero tampoco se puede concebir aislada de la sociedad como sostenían las bases filosóficas del capitalismo liberal.

El personalismo cristiano, en el que de nuevo destaca Jacques Maritain, afirma que la natural sociabilidad del ser humano se opone a la idea básica del contrato social que sostiene el sistema liberal.

Pablo VI. Cfr. C. CALDerón (1964) Iglesia con Pablo VI, Salamanca, Sígueme. Para profundizar en el pesamiento de J. Maritain Cf. J. Ramón Calo y D. BarCala (1987) El pensamiento de J. Maritain, Madrid, Cincel. M. López CASQUete de PRADO (2014) La antropología social en el pensamiento de Jacques Maritain: Humanismo integral y economía del bien común, Córdoba, Servicio de Publicaciones de la Universidad de Córdoba.

${ }_{17}$ Cf. A. Martínez Rodríguez, Heidegger y el humanismo, 8:[acceso 27.4.17] http://www.unizar.es/ arenas/Alejandro_Martinez_Heidegger_humanismo.pdf

18 Un amplio resumen sobre esta polémica puede verse en T. URDANOZ (1985) Historia de la filosofía, VIII, Madrid, BAC, 358-415. 


\section{La antropología teológica de PP}

Así las cosas, el materialismo, el humanismo y personalismo son los interlocutores del hombre de la Populorum Progressio. La teología se enfrentó al problema de responder a los retos antropológicos buscando en sus propios conceptos la imagen del hombre que fuera capaz de sustentar la creación de un mundo más humano a través del desarrollo integral. Pablo VI recurrió fundamentalmente a tres conceptos que acababan de profundizarse en el Concilio Vaticano II.

\section{3.a. La creación en Cristo}

El materialismo en sus dos formas enfrenta a la antropología teológica a dos viejas cuestiones.

La primera es aquella en la que Benedicto XVI ha insistido tanto: la relación Dioshombre. Desde la llustración han aparecido al pensamiento como ideas opuestas: Donde está Dios el hombre mengua, por tanto, siguiendo el pensamiento ilustrado, el hombre para ser lo que es debe negar a Dios. Frente a ello Pablo VI recuerda que:

No hay, pues, más que un humanismo verdadero que se abre al Absoluto en el reconocimiento de una vocación que da la idea verdadera de la vida humana (PP42).

Años más tarde, Benedicto XVI, parafraseando a Juan Pablo Il, afirmó:

¿Acaso no tenemos todos de algún modo miedo -si dejamos entrar a Cristo totalmente dentro de nosotros, si nos abrimos totalmente a él-, miedo de que él pueda quitarnos algo de nuestra vida? ¿Acaso no tenemos miedo de renunciar a algo grande, único, que hace la vida más bella? ¿No corremos el riesgo de encontrarnos luego en la angustia y vernos privados de la libertad? Y todavía el Papa quería decir: jno! quien deja entrar a Cristo no pierde nada, nada -absolutamente nada- de lo que hace la vida libre, bella y grande. ¡No! Sólo con esta amistad se abren las puertas de la vida. Sólo con esta amistad se abren realmente las grandes potencialidades de la condición humana. Sólo con esta amistad experimentamos lo que es bello y lo que nos libera. [...] ¡No tengáis miedo de Cristo! Él no quita nada, y lo da todo. Quien se da a él, recibe el ciento por uno. Sí, abrid, abrid de par en par las puertas a Cristo, y encontraréis la verdadera vida ${ }^{19}$.

La segunda cuestión a la que el materialismo enfrenta a la teología, es mucho más compleja. Ya no se trata solo de afirmar la necesidad de la apertura a lo

\footnotetext{
${ }^{19}$ BenEDICTO XVI, Homilía en la Santa Misa de imposición del palio y entrega del anillo del pescador en el solemne inicio del ministerio petrino del obispo de Roma: [acceso 27.4.17] https://w2.vatican.va/content/benedict-xvi/es/homilies/2005/documents/hf_ben-xvi_hom_20050424_inizio-pontificato.html
} 
Transcendente sino trata de dilucidar cuál es la conexión entre lo material y lo sobrenatural, cuál el lugar de la Transcendencia en el desarrollo humano. Se trata del viejo problema de la relación entre la Iglesia y el mundo, entre el Reino de Dios y la liberación humana ${ }^{20}$. Es el viejo problema del sobrenatural. Era un problema de primera magnitud en los años 60 del siglo XX del que se ocuparon los mejores teólogos: De Lubac, Rahner o Alfaro ${ }^{21}$.

En breve, la cuestión es si el hombre puede encontrar la plenitud en su propia naturaleza o no. Y si esto es cierto, cómo es posible sin comprometer la libertad de Dios. Dicho de otro modo, ¿̇el hombre tiene dos plenitudes una natural-como ser libre y racional- y otra sobrenatural -como criatura llamada a la comunión con Dios, o una sola plenitud? La cuestión no es baladí, porque si es verdad el doble fin, la justicia y el Reino de Dios son independientes; pero si solo hay una ¿̇cómo compaginar el Reino de Dios y la justicia, sin que el primero anule al segundo o sin que la segunda diluya al primero? ¿ ¿Trabajo por la justicia o por el Reino? $\bigcirc$

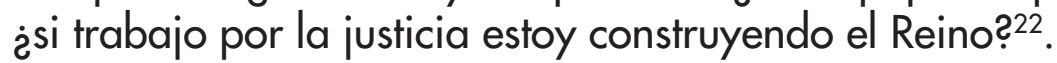

Esta problemática constituyó la esencia del debate que se produjo en torno a la teología de la liberación y que se condensó en las dos Instrucciones de la Congregación para la Doctrina de la Fe.

Pablo VI en PP 16 alude al humanismo transcendente y a la inserción en Cristo como respuesta al problema:

De la misma manera que la creación entera está ordenada a su Creador, la criatura espiritual está obligada a orientar espontáneamente su vida hacia Dios, verdad primera y bien soberano. Resulta así que el crecimiento humano constituye como un resumen de nuestros deberes. Más aun, esta armonía de la naturaleza, enriquecida por el esfuerzo personal y responsable, está llamada a superarse a sí misma. Por su inserción en el Cristo vivo, el hombre tiene el camino abierto hacia un progreso nuevo, hacia un humanismo trascendental que le da su mayor plenitud; tal es la finalidad suprema del desarrollo personal (PP 16).

${ }^{20}$ El propio Pablo VI lo ilustra con el papel de los misioneros y contribución a la humanidad (PP 12).

${ }^{21}$ La obra más importante fue H. DE LUBAC (1991) El misterio del sobrenatural, Madrid, Encuentro, pero K. Rahner también dedicó multitud de escritos a la cuestión y acuñó la expresión "existencial-sobrenatural" para dar solución al problema. J. Alfaro también dedicó numerosas páginas a este respecto, desde estudios históricos hasta tratados sistemáticos. Una bibliografía suficiente sobre el tema se puede ver en L. F. LADARIA (1997) Teología del pecado original y de la gracia, Madrid, BAC.

22 Al poco tiempo de publicarse PP, Álvarez Bolado describe muy bien este ambiente que hizo correr ríos de tinta. Cfr. A. Álvarez Bolado (1968) "Evangelio y desarrollo", en M. García, (ed.) Teología y sociología del desarrollo. Comentario a la Populorum Progressio, Madrid, Razón y Fe,78. 
La idea es compleja de explicar pero lo que Pablo VI quiere afirmar es la idea de la Gaudium et Spes de que el hombre ha sido creado a imagen y semejanza del Verbo encarnado. Dicho de otro modo:

Cristo aparece como la respuesta a los interrogantes del hombre pero no porque traiga una sabiduría nueva ignota para el hombre, sino porque en él vemos realizado el proyecto original, a imagen del que estamos hechos y que está interrumpido por el pecado. Cristo es la respuesta porque es el antitipo del hombre. Al ser propuesto como modelo del hombre no se nos propone nada sobrehumano, sino precisamente lo más humano, el modelo original ${ }^{23}$.

En definitiva: por el hecho de la creación en Cristo, el desarrollo de lo humano nos conduce la plenitud del hombre, que no es otra que Dios.

\section{3.b. Creación a imagen y semejanza}

La cuestión del humanismo, el despliegue de la existencia humana, enfrentó a la antropología teológica a otro problema, que aunque muy parecido al anterior presenta algún matiz.

El término humanismo aparece en la encíclica en 6 ocasiones, 5 de ellas en el número 42. Para PP la existencia humana es vocación, por tanto la respuesta a la cuestión del humanismo procede de quien llama, de Dios. Esta idea de PP es el centro de la antropología de Gaudium et Spes.

Los capítulos uno, dos y tres de la primera parte de la constitución conciliar suponen una descripción de los tres valores emergentes de la autoconciencia del hombre en el tiempo moderno: la subjetividad, la socialización y la historicidad.

No es este el lugar para detenerse en el comentario de estos capítulos, pero una rápida mirada hace descubrir en los tres la misma estructura que tiene en la base la clave antropológico-cristológica:

- Se afirma la creación del hombre a imagen y semejanza de Dios (GS 12, 24 y 34) en los primeros números del capítulo.

- Se describe el contenido de ese valor.

${ }^{23}$ R. Amo Usanos (2004) "La creación del hombre 'a imagen de Dios': un criterio de juicio sobre la suficiencia del modelo antropológico de la bioética católica", Scripta Fulgentina XIV, 107. 
- Se advierte del daño causado por el pecado en el ejercicio de esa dimensión.

- Se termina haciendo alusión a que la creación a imagen y semejanza adquiere su plenitud en Cristo (GS 22, 32 y 38).

Esta estructura de los capítulos muestra la tensión entre creación y redención. El hombre aparece, por un lado, creado a imagen de Cristo y, por otro, su plenitud es Cristo. Los dos polos de su existencia son Cristo y, por tanto, el despliegue de su existencia es Cristo.

Dicho de otro modo, el humanismo integral, propuesto por el Concilio y Pablo VI, piensa al hombre como la curva de una asíntota. Aquella línea recta que, prolongada indefinidamente, se acerca progresivamente a una curva sin llegar nunca a encontrarla, más que en el infinito.

La asíntota es Cristo y la curva el hombre. Creado a imagen de Dios -de Cristotiende a asemejarse a él. En los dos puntos infinitos -Creación y Redención- el hombre se encuentra con Cristo. Por eso es Cristo el que revela al hombre la verdad sobre el propio hombre ${ }^{24}$ y el dinamismo de la existencia humana es proceso de asemejamiento del hombre a Cristo en el acto redentor. Por creación somos imagen de Cristo y en el despliegue de nuestra existencia debemos asemejarnos a Cristo redentor. Este es el humanismo cristiano, este es el verdadero desarrollo humano, el que lleva al hombre hasta el infinito.

\section{3.c. Antropología del desarrollo solidario}

El hecho de la sociabilidad humana es el dato que soporta el desarrollo solidario del que habla Populorum Progressio (PP 43). Como se ha indicado el hombre pertenece a la sociedad. Ahora bien, en tiempos de Pablo VI y del Concilio Vaticano II, la sociabilidad era un dato en el que teológicamente no se había profundizado. Es curioso comprobar como el capítulo Il de la primera parte de Gaudium et Spes, dedicado a la Comunidad humana, fundamenta la sociabilidad en la naturaleza humana (GS12) o en Hechos de los Apostoles 17, $26^{25}$.

\footnotetext{
${ }^{24}$ Cf. Juan Pablo II, Redemptor hominis 10. Se utiliza el texto de la página web del Vaticano: [acceso 27.4.17] http://w2.vatican.va/content/john-paul-ii/es/encyclicals/documents/hf_ipii_enc_04031979_redemptor-hominis.html

${ }^{25}$ Cfr. GS 24.
} 
La insistencia trinitaria del Concilio Vaticano II ha provocado que la teología profundice en la interpretación trinitaria de la creación a imagen y semejanza de Dios para fundamentar la antropología de la sociabilidad humana. Así, la reciente antropología teológica y el magisterio han optado por la exégesis que, entre otros hacen San Agustín ${ }^{26}$ de Gen 1, 27 afirmando que el hombre ha sido creado a imagen de la Trinidad; frente a la exégesis asiática de Ireneo ${ }^{27}$ y Tertuliano ${ }^{28}$, que recoge la misma Gaudium et Spes (GS 22) y que interpreta que el hombre ha sido creado a imagen del Verbo encarnado.

El Compendio de doctrina Social de la Iglesia es la máxima expresión de esta nueva forma de dar cobertura teológica al dato de la sociabilidad humana y, por tanto, de dar fundamento a la necesidad de que el desarrollo humano sea solidario.

El mensaje fundamental de la Sagrada Escritura anuncia que la persona humana es criatura de Dios (cf. Sal 139,14-18) y especifica el elemento que la caracteriza y la distingue en su ser a imagen de Dios: "Creó, pues, Dios al ser humano a imagen suya, a imagen de Dios le creó, macho y hembra los creó» $(G n 1,27)$... La semejanza con Dios revela que la esencia y la existencia del hombre están constitutivamente relacionadas con Él del modo más profundo. Es una relación que existe por sí misma y no llega, por tanto, en un segundo momento ni se añade desde fuera. [...] La persona humana es un ser personal creado por Dios para la relación con Él, que sólo en esta relación puede vivir y expresarse, y que tiende naturalmente hacia Él. [...] La relación entre Dios y el hombre se refleja en la dimensión relacional y social de la naturaleza humana. El hombre, en efecto, no es un ser solitario, ya que "por su íntima naturaleza, es un ser social, y no puede vivir ni desplegar sus cualidades, sin relacionarse con los demás»29.

\section{Riesgos y retos de la antropología teológica de PP}

Una vez en este punto, expuesto el diálogo entre la antropología teológica y el pensamiento antropológico de mediados del siglo XX, llega el momento de traerlo al presente. Cincuenta años después hay que poner de manifiesto los riesgos y retos que afronta la antropología teológica de PP en la actualidad.

\footnotetext{
${ }^{26}$ S. Agustín, De Trinitate XV, 23, 43.

27 S. IRENEO, Adversus Haereses, V, 6.

28 Tertuliano, De Carne Resurreccione 6.

${ }^{29}$ Compendio de Doctrina Social de la Iglesia, 108-1 10: [acceso 27.4.17] http://www.vatican.va/ roman_curia/pontifical_councils/justpeace/documents/rc_pc_justpeace_doc_20060526_compendio-dott-soc_sp.html
} 


\section{4.a. El riesgo de la tecnocracia y el reto de la dignidad humana}

El pasado 3 de abril de 2017 en la marco del congreso celebrado en Roma a propósito del 50 aniversario de PP, el Cardenal Müller abordaba en su intervención la antropología de esta encíclica ${ }^{30}$. Allí hablaba de los nuevos riesgos y afirmaba el peligro de las nuevas formas totalitarias del desarrollo herederas del materialismo. Entre otras citaba el utilitarismo y la tecnocracia.

Creo que hay que seguirle la pista a esta última sobre la que ya advertía Pablo VI:

la tecnocracia del mañana puede engendrar males no menos temibles que el liberalismo de ayer. Economía y técnica no tienen sentido sino es por el hombre, a quien deben servir (PP34).

Pues bien, el mañana ya ha llegado. Francisco en Laudato si' afirma:

El paradigma tecnocrático se ha vuelto tan dominante que es muy difícil prescindir de sus recursos, y más difícil todavía es utilizarlos sin ser dominados por su lógica [...] El paradigma tecnocrático también tiende a ejercer su dominio sobre la economía y la política. La economía asume todo desarrollo tecnológico en función del rédito, sin prestar atención a eventuales consecuencias negativas para el ser humano [...] Con sus comportamientos expresan que el objetivo de maximizar los beneficios es suficiente. Pero el mercado por sí mismo no garantiza el desarrollo humano integral y la inclusión socia ${ }^{31}$.

El decir, el nuevo nombre del materialismo es tecnocracia que pone en el centro del cosmos axiológico, no al hombre -por su dignidad- sino a la técnica -por su eficacia económica, maximizando el beneficio.

El reto, por tanto, para las ciencias económicas y empresariales será mostrar que maximizar la dignidad es mejor que maximizar solo el beneficio. Si el centro de la economía y de la empresa es el hombre, todo el hombre; economía y empresa no deben buscar maximizar los aspectos materiales del ser humano sino maximizar al hombre entero. En otras palabras, la antropología teológica debe ayudar en este diálogo interdisciplinar a poner la dignidad del hombre como el valor principal el cual se debe maximizar.

Esto es lo que quiso decir PP 16 cuando hablaba de que el hombre por su inserción en el Cristo vivo el hombre tiene el camino abierto hacia un progreso nuevo,

\footnotetext{
${ }^{30}$ Puede verse en Youtube: [acceso 27.4.17] https://www.youtube.com/watch?v=mBknSNqYfqw

${ }^{31}$ Francisco, Laudato si', 108-109. Se utilizará como abreviatura LS y el texto es el de la página web del Vaticano: [acceso 27.4.17] http://w2.vatican.va/content/francesco/es/encyclicals/documents/ papa-francesco_20150524_enciclica-laudato-si.html
} 
hacia un humanismo trascendental que le da su mayor plenitud y que resumió Benedicto XVI al afirmar que "El anunció de Cristo es el primero y principal factor de desarrollo" (Civ 8).

\section{4.b. El riesgo del subdesarrollo moral y el reto horizonte del pluralismo ético}

El papa Bendicto XVI en Caritas in Veritate 29 vuelve a recordar el riesgo del que habló PP 19 y SRS 28: el subdesarrollo moral. Este es el riesgo que sigue amenazando al desarrollo del hombre y que en el fondo significa que el límite asintótico que se propone no es Cristo, no es la verdad sobre el hombre.

El riesgo es el de los nuevos humanismos existencialistas (que no tienen nombre y rostro tan claro en esta segunda década del siglo XXI), que no armonizan adecuadamente libertad y verdad y condenan al hombre a la libertad, como ya lo hizo Sartre.

La reflexión humanista sigue en pie: el ser humano no es inmóvil ni estático ${ }^{32}$. No es una esencia cerrada, sino que debe moverse con libertad en su "actus essendi", en su existencia. Ahora bien, el riesgo que se vio cumplido, entre otras cosas en el subdesarrollo moral que contribuyó a la crisis económica pasada, continúa y Benedicto XVI no para de poner lo de manifiesto: la vocación cristiana a dicho desarrollo abarca tanto el plano natural como el sobrenatural; éste es el motivo por el que, "cuando Dios queda eclipsado, nuestra capacidad de reconocer el orden natural, la finalidad y el "bien", empieza a disiparse" (CiV 18) $)^{33}$.

El reto que se plantea es el afrontar esta antropología en vocativo o antropología asintótica, en el escenario del pluralismo ético. En cierta manera Juan Pablo II propone la salida:

no sería verdaderamente digno del hombre un tipo de desarrollo que respetara y promoviera los derechos humanos, personales y sociales, económicos y políticos (SRS 33).

\footnotetext{
32 JUAN PABLO II, Sollicitudo Rei Socialis 30. A partir de ahora se utilizará la abreviatura SRS y como texto se utiliza el de la página web del Vaticano: [acceso 27.4.17] http://w2.vatican.va/content/ john-paul-ii/es/encyclicals/documents/hf_ip-ii_enc_30121987_sollicitudo-rei-socialis.html

${ }^{33}$ Cfr. J. M. Aparicio (2014) "Desarrollo humano integral", en J. Sols LucIA (ed.) Pensamiento social cristiano abierto al siglo XXI. A partir de la encíclica Caritas in Veritate, Santander, Sal Terrae, 38.
} 
La antropología que subyace de la Declaración de Derechos del Hombre puede ser un buen punto de encuentro para indicar el horizonte, la asíntota, en un mundo éticamente plural.

\section{4.c. El riesgo del antropocentrismo desviado y el reto de la ecología integral}

El papa Francisco en la encíclica Laudato si' le ha puesto un nuevo rostro al personalismo individualista del que hablaba Pablo VI en Populorum Progressio, es lo que llama antropocentrismo desviado que coloca al hombre ya no solo aislado del resto de individuos, como hacia el antiguo individualismo, sino que lo aísla del medio ambiente.

Laudato si' ha supuesto uno de los mayores avances en el magisterio referente a la antropología teológica desde hace siglos, en la medida que ha asumido como propia la cosmovisión de un universo en evolución en que la pieza clave es el sistema termodinámicamente abierto, es decir, el ser vivo. En virtud de la "apertura" es decir, en función de la necesidad de neguentropía, es como se justifica la repetida expresión de Laudato si': "todo está conectado"34. De este modo el ser humano y su desarrollo no debe ser solo solidario con "todos los hombres", sino que ha de tener en cuenta "toda la creación".

Este riesgo lleva en sí mismo el nuevo reto que Francisco resume en el número 119 de Laudato si': encontrar la armonía entre la apertura al Transcendente, a los hombres y a la creación:

Porque no se puede proponer una relación con el ambiente aislada de la relación con las demás personas y con Dios. Sería un individualismo romántico disfrazado de belleza ecológica y un asfixiante encierro en la inmanencia ${ }^{35}$.

\section{Conclusión}

En conclusión, han pasado 50 años de Populorum Progressio y, con la distancia, se puede comprobar que fue un texto no solo magisterial sino magistral por dos motivos.

\footnotetext{
${ }^{34}$ Cfr. LS 16, 91, 117, 138, 240

${ }^{35}$ LS 119.
} 
El primero, porque mostró cómo hacer de la Doctrina Social de la Iglesia un elemento de evangelización, buscando los "criterios de juicio, los valores determinantes, los puntos de interés, las líneas de pensamiento, las fuentes inspiradoras y los modelos de vida de la humanidad"36. La Doctrina Social de la Iglesia nunca había sido un discurso cerrado en si mismo, como si tratase de cuestiones bizantinas, pero con Pablo VI su capacidad de diálogo con el mundo alcanzó cotas muy difícilmente repetibles, por eso se convirtió en una nueva voz para nuestra época ${ }^{37}$.

El segundo, porque sigue teniendo una fuerza profética que alcanza nuestros convulsos compases iniciales del siglo XXI. Precisamente por buscar las raíces antropológicas nunca perderá esa capacidad, ya que la cuestión del hombre, la antropología, es siempre actual. Por hablar del hombre, Populorum Progressio sigue siendo una propuesta actual a un mundo, del que Poupard ya decía que era inhumano y que por desgracia-si no ponemos remedio-podemos comprobar día a día que no se equivocaba.

\footnotetext{
${ }^{36}$ PABLO VI, Evangelii Nuntiandi, 19. Se utiliza el texto de la página web del Vaticano: [acceso 27.4.17] http://w2.vatican.va/content/paul-vi/es/apost_exhortations/documents/hf_p-vi_exh_19751208_ evangelii-nuntiandi.html

${ }^{37} \mathrm{Cfr}$. PP 47
} 